\title{
PREPARATORY STAGES OF HETEROCAMPA UNICOLOR PACK.
}

\author{
BY HARRISON G. DYAR, NEW YORK.
}

The eggs were not observed but I believe that I have found the larva in its first stage which is as follows:-

First stage.-Head cordate, black, shiny, a large white patch in front covering the clypeus and labrum; width .4 mm. Body enlarged dorsally at joint 2 and bearing on each side of the cervical shield a smooth elongated process (.4 mm.) of uniform thickness tipped by a fine short hair. The anal feet are prolonged into a pair of smooth processes or imperfect stemapoda, a little enlarged at the end and minutely hairy below. Body cylindrical, smooth, shiny, pale green with four fine red-brown lateral lines on each side, the uppermost faint; three patches of red-brown, the first on joint 2 dorsally, the second on joint 7 dorsally and laterally and the third on joint II and joint I 2 anteriorly dorsally running forward upon joint ro above the feet. Cervical shield and "horns" and anal plate black. Stemapods I mm. long, green, twice ringed with black, the swollen ends red-brown. The legs on joints 7 and ro are black outwardly. Venter pale whitish throughout. During this stage the larva eats only the lower half of the leaf.

Second stage.-Head slightly bilobed, flat in front, pale whitish, more distinctly white in a large patch covering the clypeus. A broad diffuse red-brown band runs to the vertex of each lobe. Ocelli black; width of head $.7 \mathrm{~mm}$. Cervical horns short, black, arising from swollen bases and each tipped by a short hair; stemapods $1.2 \mathrm{~mm}$. long, pale yellowish, with a few black dots near the center, the terminal extensile portion crimson preceded by a black ring. Body pale greenish, not shiny; joints 2, 7, I I and I3 red-brown above as are the feet on joints 7 and ro. A broad irregular brown dorsal shade and four fine red-brown lateral lines somewhat indistinct on joints 8-ro. As the stage advances all the red-brown fades out except on the cervical shield; the dorsal shade becomes a band, contracted at the segmental sutures and enlarged on joints 7 and I I. During this stage and subsequently the larva eats the whole leaf.

Third stage.-Head slightly bilobed, flat in front, rounded and narrowing a little to the vertex; pale whitish green, a broad diffuse brown band on each lobe from the ocelli to vertex; ocelli black; width $1.35 \mathrm{~mm}$. Cervical horns are two short black tubercles on the cervical shield; stemapods $2 \mathrm{~mm}$. long, faintly reddish with a few elevated black dots, especially below and outside, the tips a little swollen and crimson. Body whitish with three fine faint white lines on each side of the reddish brown dorsal band which is very distinct, covering the cervical shield and anal plate, retracted at each suture and widening on joints 7 and II more than on the other segments. Feet and venter concolorous with the body. As the stage advances the body becomes green, the bands on the head and the dorsal band of the body become edged with white and the two remaining narrow undulated subdorsal lines, pale yellow.

Fourth stage.-Head not distinctly bilobed, about as high as wide, flat in front and narrowing toward the vertex; width $2.1 \mathrm{~mm}$; marked as before, the inner white border of the brown bands very broad, covering nearly all of the front of the head except the clypeus and central suture; antennae and mouth parts whitish; maxillae black inwardly. Cervical horns reduced to mere points; stemapods $2.5 \mathrm{~mm}$. long, whitish, shaded with red brown at the bases and ends, the few minutely piliferous elevated dots brown, and the extensile part white. Body marked 
as before; the dorsal band of nearly uniform width, retracted at the sutures, hardly distinctly wider on joint 7 , considerably widened on joint II, expanded on joint 2 to cover the rudimentary horns and faint on the anal plate. Length after molt, $15 \mathrm{~mm}$. As the stage advances the broad inner borders of the bands on the head fade out near the bands leaving a white line bordering the clypeus and central suture; the dorsal band becomes partly mottled with its white borders which are yellow at the sutures; there is a trace of a yellow stigmatal line and the sides have a few black specks at the extremities. Spiracles ocher, surrounded by yellow.

Fifth stage.-Head rounded, flat in front, pale green, the broad brown bands extending from before the ocelli to the vertex of each lobe slightly mottled and bordered behind with yellow and before faintly with white. A white line starts on each side of the clypeus a little above its base and borders it, running close to the central suture and becoming merged at the vertex in the borders of the brown bands; ocelli and maxillae inwardly black; mandibles and antennae white; width $3.2 \mathrm{~mm}$. Body as before, cervical processes absent, stemapods relatively shorter $(2 \mathrm{~mm})$. Color green, a broad red-brown dorsal band mottled and streaked on a white ground, extended in two small distinct spots on joint 2 which represent the cervical "horns" and on joint II containing a V-shaped brown line which is repeated more faintly on joint $\mathbf{I} 2$. The stemapods are white, brown inwardly and speckled with brown outwardly with a few minute hairs. In the segmental sutures the dorsal band is slightly retracted and is yellow; a narrow yellow sub-dorsal line and a waved suprastigmatal line besides a stigmatal line on joints 3 and 4 . Spiracles ocher, paler centrally and surrounded by a whitish shade; a white subventral band on joints II-13. Feet concolorous with body. A number of dark purple specks over the sides especially on joints 2-4 and II-I2. As the stage advances a marked change takes place. The head becomes finely reticulated with brown except on clypeus and mouth and the white marks become faint; the body except in the dorsal band and on the venter is heavily spotted with brown, the spots small but so thick that some become confluent. They tend to segregate in parallel longitudinal lines between the lateral yellow lines and are absent on the cervical shield and anal plate which are both large, the former semicircular. The color of the body fades to sordid greenish white and the brown of the dorsal band fades out leaving it creamy white with a fine brown line very near each edge, brown intersegmental marks, a broad brown central streak on joint 7 and on the anal plate and the ir regular V-shaped mark on joint II. The spiracles are each surrounded by a brown ring. Length at maturity $50 \mathrm{~mm}$.

Cocoon. - Formed between two leaves: semi-transparent, similar to that of Schizura leptinoides but less perfect and weaker.

Pupa.-Cylindrical, gently tapering to the extremities; thorax and wing cases moderately prominent; at the posterior edge of the thorax, a curved row of rounded cutical granulations. Cases densely creased, body more sparsely punctured. The cremaster consists of two separate, short, conical projections, their sharp ends curved almost straight outward, above which is a curved row of about a dozen narrow carinated ridges $0.5 \mathrm{~mm}$. long, parallel to the length of the body. Length $20 \mathrm{~mm}$; width $7 \mathrm{~mm}$.

Food plant.--Sycamore (Acerpseudo-plantanus).

Larva from Dutchess Co., New York. 

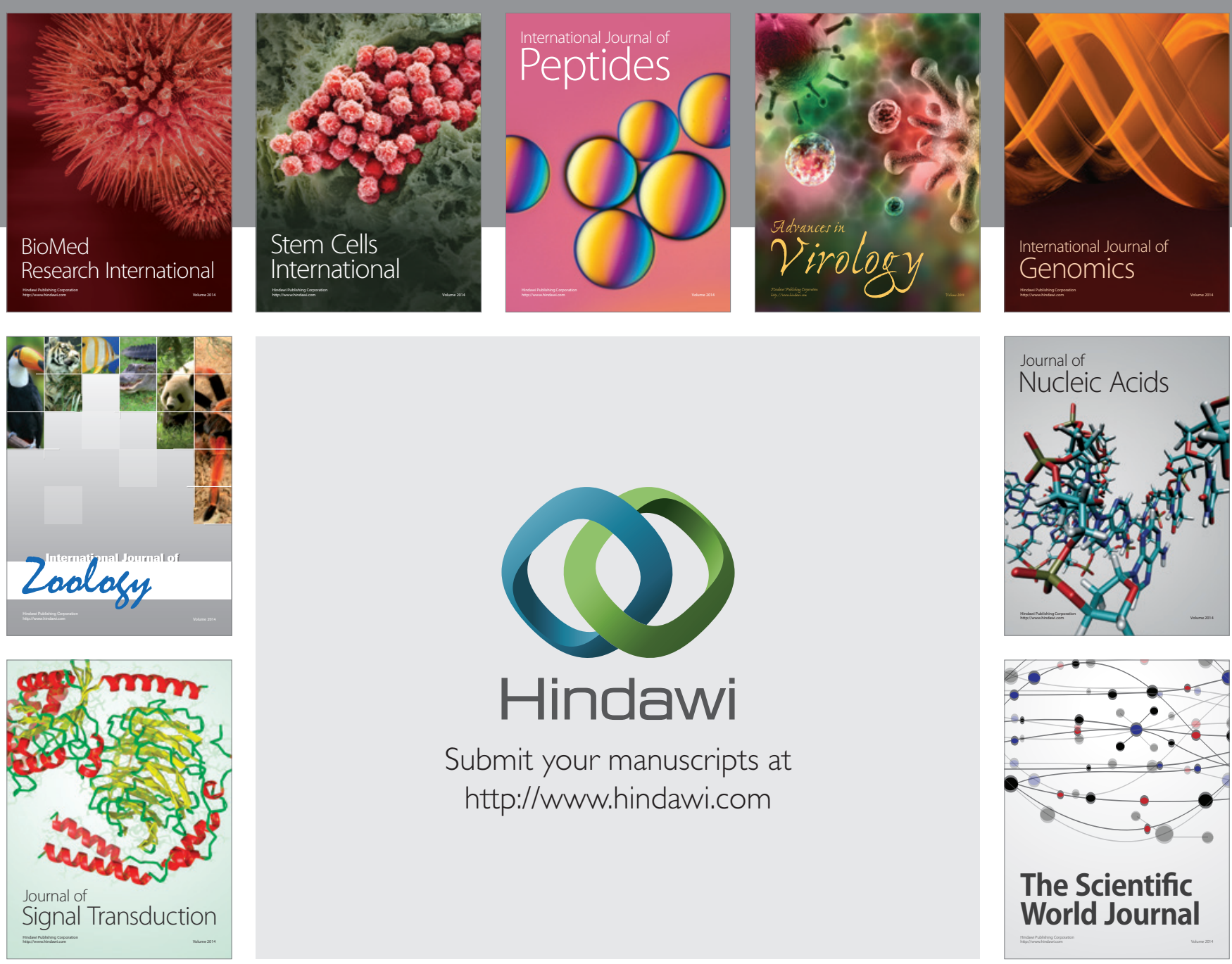

Submit your manuscripts at

http://www.hindawi.com
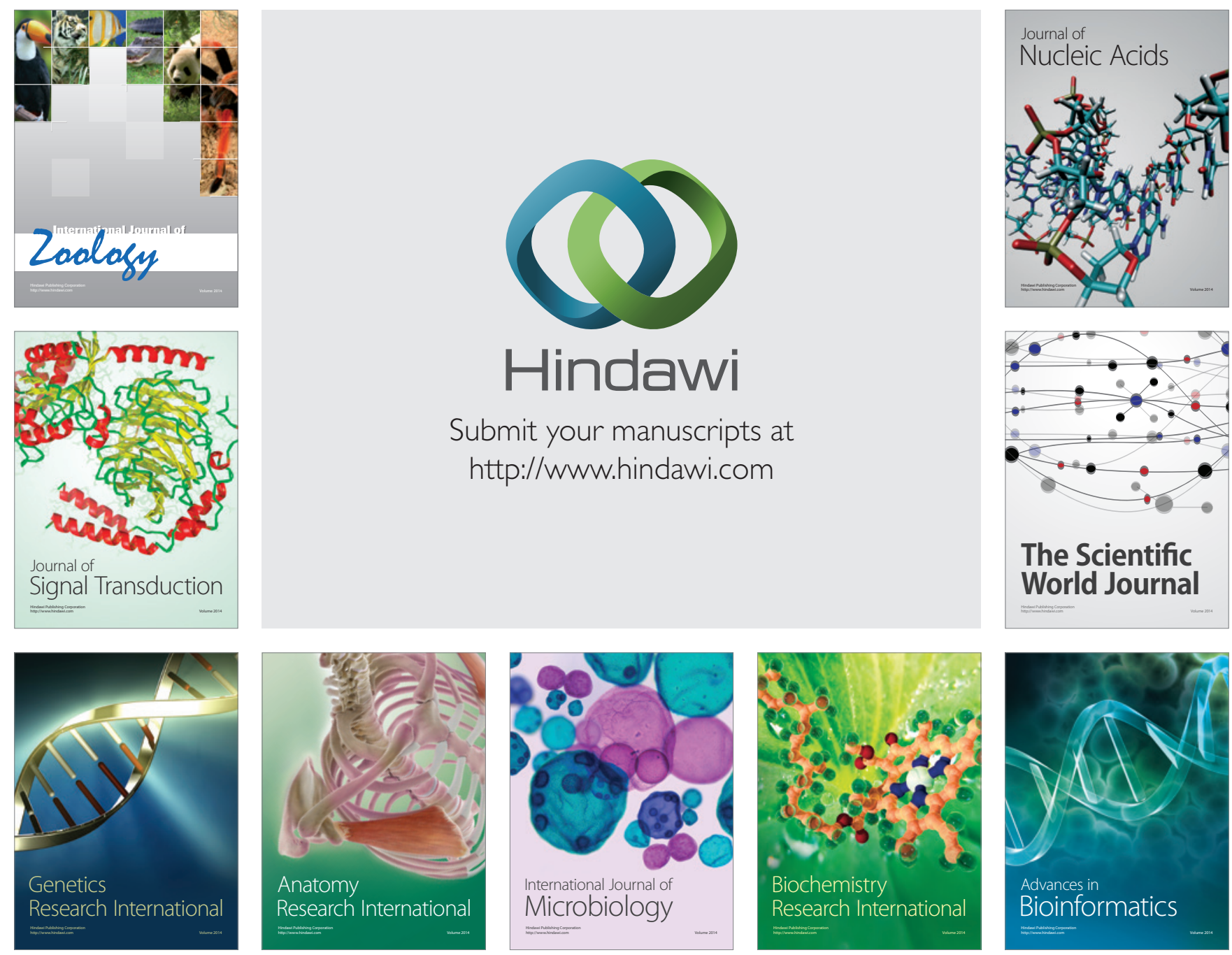

The Scientific World Journal
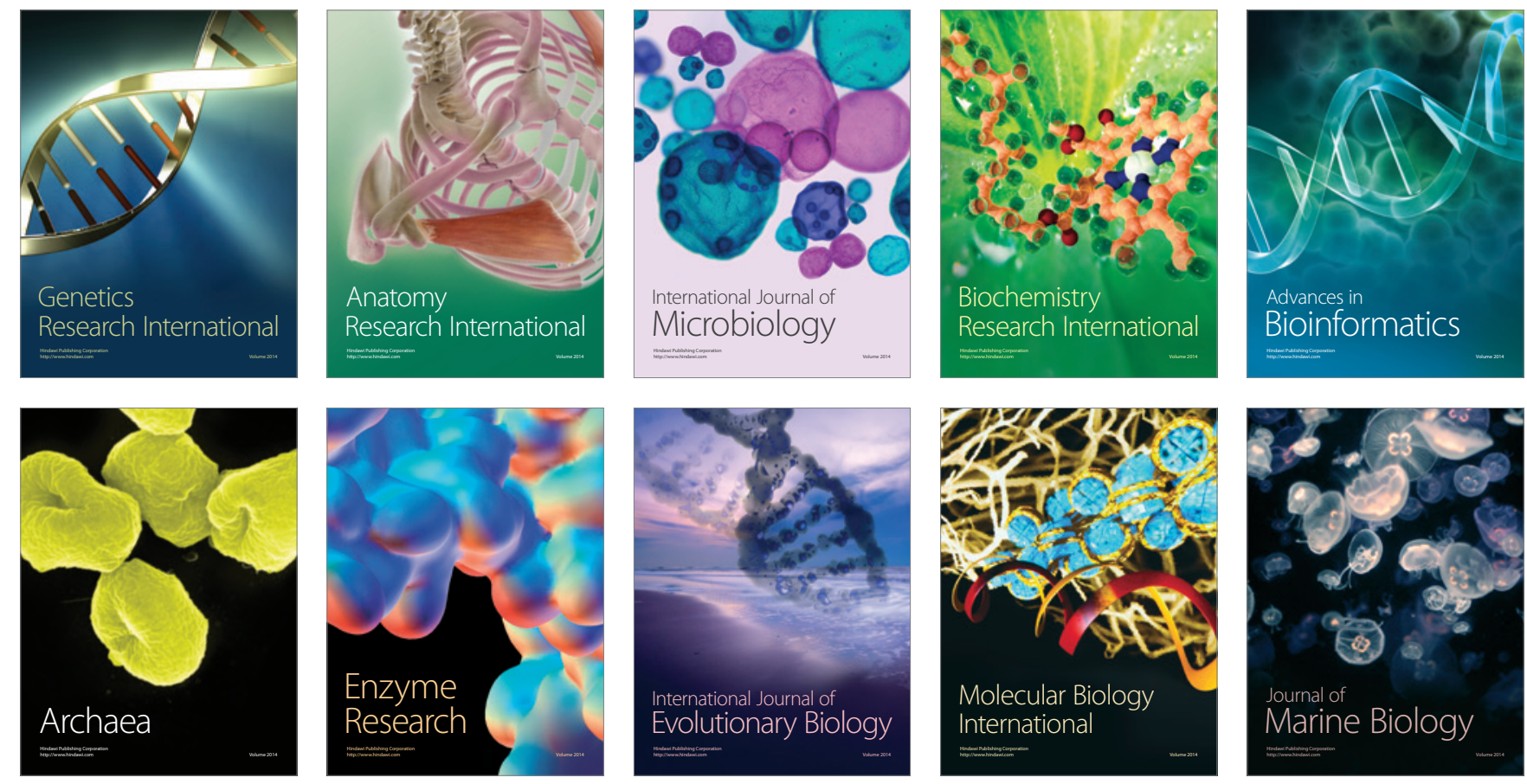